\title{
ON TWO PROBLEMS FOR GAUSS COMPOUND MEAN
}

\section{LADISLAV MATEJÍ́̌KKA}

Abstract. In this paper, we give answers to two open problems concerning Gauss Compound mean posed in the paper: [ZH. H. YANG, A New Proof of Inequalities for Gauss Compound Mean, Int. Journal of Math. Analysis, Vol. 4, (2010), no. 21, 1013-1018.] One of the problems is equivalent to the Vamanamurthy problem.

Mathematics subject classification (2010): 26D07, 26E60.

Keywords and phrases: Gauss compound mean, logarithmic mean, inequality, open problems.

\section{REFERENCES}

[1] J. M. Borwein And P. B. Borwein, Pi and the AGM, John Wiley and Sons, New York (1987).

[2] J. M. BORWEIN AND P. B. BORWEIN, Inequalities for compound mean iterations with logarithmic asymptotes, J. Math. Anal. Appl. 177 (1993), no. 2, 572-582.

[3] T. BURIĆ, N. Elezović, Asymptotic expansion of the arithmetic-geometric mean and related inequalities, Journal of Mathematical Inequalities 9 (2015), 1181-1190.

[4] B. C. CARLSON AND M. VuORINEn, An inequality of the AGM and the logarithmic mean, SIAM Rev. 33 (1991), 655, Problem 91-117.

[5] E. Neuman And J. SÁNDOR, On certain means of two arguments and their extensions, Intern. J. Math. Math. Sci. 2003, no. 16, 981-993.

[6] M. K. Vamanamurthy and M. Vuorinen, Inequalities for means, J. Math. Anal. Appl. 183 (1994), no. 1, 155-166.

[7] ZH. H. YANG, Some identities for means and applications, RGMIA Res. Rep. Coll. 8 (2005), no. 3 Art. 17; available online at http://rgmia.vu.edu.au/v8n3.html.

[8] ZH. H. YANG, A New Proof of Inequalities for Gauss Compound Mean, Int. Journal of Math. Analysis, Vol. 4, (2010), no. 21, 1013-1018.

[9] ZH. H. YANG, Y. Q. SONG AND Y. M. CHU, Sharp bounds for the arithmetic-geometric mean, J. Inequal. Appl. (2014): 192, available online at

http://www. journalof inequalitiesandapplications.com/content/2014/1/192. 